\title{
Konseling Lansia: Upaya Lanjut Usia dalam Membangun Kemandirian Hidup dan Penerimaan Diri Terhadap Kesiapan Memasuki Masa Pensiun (Studi Pada Lansia di Bina Keluarga Lansia Posyandu Cempaka Kabupaten Ngawi)
}

\author{
Diana Ariswanti Triningtyas ${ }^{1}$, Siti Muhayati ${ }^{2}$ \\ Program Studi Bimbingan dan Konseling FKIP Universitas PGRI Madiun ${ }^{1}$, \\ Program Studi Pendidikan Teknik Elektro FKIP Universitas PGRI Madiun² \\ Email: dianaariswanti@unipma.ac.id ${ }^{1}$, sitimuhayati10@gmail.com²
}

\begin{abstract}
:
In Indonesia, there are currently around 21 million elderly people or about $9.6 \%$ of the entire population of Indonesia. This shows that the Indonesian state has begun to belong to the aging population group. This research is motivated by the motivation of how to work for the elderly in building the independence of life. The purpose of the research is to describe and analyze the psychological impacts that affect the readiness to enter retirement, as well as how to build life independence and self-acceptance towards readiness to retire. The research design is qualitative descriptive. The sampling technique uses purposive sampling. Sources of data are obtained from informants, places, events and documents. Data collection techniques through participatory observation, in-depth interviews and documentation. Data analysis is carried out through stages, namely the data reduction stage, data presentation stage, and conclusions. Data validity, with technical triangulation, is by checking data to the same source with different techniques. The results of the study indicate that the independence of life of the elderly is relative. Psychological impacts that arise in the readiness to enter retirement for the elderly include aspects of health, economic aspects and social aspects. Understanding and building self-reliance and self-acceptance of readiness to retire in the Ngawi Cempaka Posyandu Family Elderly through Elderly Counseling.
\end{abstract}

Keyword: Independence of Life, Self Acceptance, Elderly Counseling

Received August 23, 2018; Revised September 03, 2018; Accepted October 01, 2018

How to Cite: Triningtyas, D. A., \& Muhayati, S. (2018). Konseling Lansia: Upaya Lanjut Usia dalam Membangun Kemandirian Hidup dan Penerimaan Diri Terhadap Kesiapan Memasuki Masa Pensiun (Studi Pada Lansia di Bina Keluarga Lansia Posyandu Cempaka Kabupaten Ngawi). JKI (Jurnal Konseling Indonesia), 4(1), 16-21.

This is an open access article distributed under the Creative Commons 4.0 Attribution License, which permits unrestricted use, distribution, an reproduction in any medium, provided the original work is properly cited. @2018 by author and Universitas Kanjuruhan Malang. 


\section{PENDAHULUAN}

Bekerja merupakan suatu kegiatan atau aktivitas yang dilakukan oleh individu untuk memenuhi kebutuhannya (Barlian, 2016). Pada fase tertentu, individu akan menghadapi kenyataan bahwa, tidak selamanya akan bekerja. Seiring berjalannya waktu, individu akan melepas pekerjaan atau jabatan yang menjadi tugas serta tanggung jawabnya dan tiba saatnya untuk tidak bekerja lagi. Pelepasan masa jabatan atau pekerjaan ini sering disebut dengan pensiun. Pensiun adalah suatu kondisi dimana seseorang berhenti dari suatu pekerjaan yang ditekuninya, yang berarti berhentinya seseorang dalam mencari nafkah bagi keluarganya (Hurlock, 2008). Sebab, setiap orang dewasa yang bekerja baik di instansi negeri maupun swasta, akan menjadi tua dan proses menua itu tidak dapat dihindari oleh siapapun.

Indonesia saat ini terdapat sekitar 21 juta lansia atau sekitar 9,6\% dari seluruh penduduk Indonesia. Hal ini menunjukkan bahwa negara Indonesia sudah mulai masuk dalam kelompok negara berstruktur tua (aging population). Hasil proyeksi sampai dengan tahun 2050 menunjukkan jumlah penduduk Indonesia akan mencapai sekitar 314 juta jiwa (BPS) dan diperkirakan jumlah total lansia adalah 69,5 juta jiwa. Meningkatnyajumlah penduduk lanjut usia akan menimbulkan berbagai persoalan dan permasalahan bagi keluarga, masyarakat dan lanjut usia sendiri (BKKBN, 2015).

Berbagai macam persoalan hidup yang dihadapi oleh lanjut usia baik fisik maupun secara psikososial akan saling berinteraksi satu sama lain (Marlita, Saputra, \& Yamin, 2018). Secara umum bahwa kondisi fisik seseorang yang telah memasuki masa lanjut usia akan mengalami penurunan. Penurunan kondisi fisik lanjut usia ini akan berpengaruh pada kondisi psikis. Kesiapan para lanjut usia dalam menghadapi beragam permasalahan yang multi-dimensi yaitu secara fisik, psikologis, ekonomi, sosial dan spiritual, idealnya lanjut usia mampu menyelesaikan tugas-tugas perkembangannya. Perjalanan hidup individu lanjut usia seperti halnya periode lain dalam perkembangan, juga akan ditandai oleh adanya tugas-tugas perkembangan yang harus dijalani di dalam masa hidupnya sesuai dengan norma masyarakat dan norma budaya (Mönks, Knoers, \& Haditono, 1985). Salah satu faktor yang mempengaruhi keberhasilan lanjut usia ini adalah membangun kemandirian hidup.

Membangun kemandirian hidup bagi lanjut usia merupakan salah satu aspek penting yang harus dimiliki. Kemandirian hidup yang dimaksud dalam hal ini meliputi tanggung jawab, mandiri, pengalaman praktis dan akal sehat yang relevan, otonom, kemampuan memecahkan masalah, kebutuhan akan kesehatan yang baik dan juga support sosial. Salah satu komponen kebahagiaan bagi lanjut usia dalam membangun kemandirian hidup adalah penerimaan diri.

Penerimaan diri adalah memiliki penghargaan yang tinggi terhadap diri sendiri, atau tidak bersikap sinis terhadap diri sendiri; penerimaan diri berkaitan dengan kerelaan membuka diri atau mengungkapkan pikiran, perasaan, dan reaksi terhadap orang lain (Supratiknya, 1995). Individu yang mampu menerima dirinya adalah individu yang dapat menerima kekurangan dirinya sebagaimana kemampuannya untuk menerima kelebihannya. Tingkat kemampuan dalam penerimaan diri yang dimiliki oleh setiap individu adalah berbedabeda.

Hasil observasi awal yang diperoleh di lapangan menunjukkan berbagai permasalahan yang terjadi karena ketidaksiapan lanjut usia dalam menerima semua perubahan yang terjadi dan harus dihadapi. Terdapat beberapa lanjut usia yang mengalami beban mental yang ada dalam dirinya, seperti perasaan akan berkurangnya penghormatan orang lain terhadap dirinya, adanya ketakutan terhadap kegiatan yang belum jelas untuk dijalani ketika sudah memasuki masa pensiun serta faktor lain seperti berkurangnya pendapatan maupun fasilitas yang diterima. Oleh sebab itu, sangat penting bagi seseorang untuk mempersiapkan diri menghadapi usia lanjut. Fokus penelitian ini adalah upaya lanjut usia dalam membangun kemandirian hidup dan penerimaan diri terhadap kesiapan memasuki masa pensiun.

Masa pensiun sering dianggap sebagai suatu kenyataan yang tidak menyenangkan, terlebih mereka yang terbiasa bekerja, dikarenakan perubahan drastis yang akan dihadapinya nanti (Yusuf, Nihayati, \& Abidin, 2017). Perubahan yang terjadi merupakan perubahan yang penting dalam hidup seseorang, individu yang tadinya bekerja menjadi tidak bekerja, berkurangnya penghasilan, berkurangnya interaksi dan relasirelasi, dan meningkatnya waktu luang, seperti yang dipaparkan oleh (Safitri, 2013). Lebih jauh, (Fardila, Rahmi, \& Putra, 2017) menjelaskan bahwa terdapat beberapa aspek persiapan dan kesiapan pribadi individu yang merupakan kebutuhan utama untuk mempersiapkan dalam memasuki masa pensiun, yaitu 1) kesiapan materi finansial berupa ketersediaan sejumlah bekal pendukung berupa tabungan, asuransi, simpanan atau aset dan kegiatan usaha; 2) kesiapan fisik, dengan semakin bertambahnya usia maka kemampuan fisik pun akan semakin berkurang sehingga perlunya menjaga kesehatan fisik dengan menjalankan pola hidup yang benar; 3) kesiapan mental dan emosi, yakni kekuatan dan kemampuan beradaptasi dengan perubahan yang 
akan terjadi, seperti perubahan status, kehilangan pekerjaan, pengurangan pendapatan, dan kehilangan kemampuan. Dan kemampuan dalam penerimaan diri yang dimiliki seseorang berbeda-beda tingkatannya karena kemampuan tersebut dipengaruhi oleh berbagai faktor.

\section{METODE PENELITIAN}

Metode penelitian ini adalah kualitatif deskriptif (Hammersley, 2018). Teknik sampling menggunakan Purposive Sampling (Etikan, Musa, \& Alkassim, 2016). Sumber data diperoleh dari informan, tempat, peristiwa dan dokumen. Teknik pengumpulan data melalui observasi partisipatif, wawancara mendalam dan dokumentasi. Instrumen penelitian menggunakan alat ukur berupa kuesioner. Analisa data dilakukan melalui tahapan, yaitu tahap reduksi data, tahap penyajian data, dan tahap penarikan kesimpulan. Validitas data, dengan triangulasi teknik yaitu dengan melakukan cek data kepada sumber yang sama dengan teknik yang berbeda.

\section{HASIL}

Dalam penelitian ini, yang menjadi subjek penelitian adalah para lanjut usia yang telah berusia $50-70$ tahun, dengan jumlah sampel penelitian sebanyak 16 orang yang berusia lanjut. Penelitian dilakukan di Bina Keluarga Lansia (BKL) Posyandu Cempaka Kabupaten Ngawi. Hasil penelitian di lapangan diperoleh informasi bahwa para lanjut usia ini memiliki pandangan yang berbeda-beda dalam menyikapi saat memasuki masa usia lanjut. Menjadi tua, menurut sebagian besar mereka (para lanjut usia) merupakan hal yang wajar dan mau tidak mau haruslah dijalani. Secara psikologis, keadaan tersebut dapat menimbulkan masalah-masalah baru dalam kehidupan para lansia apabila kesiapan memasuki masa pensiun ini kurang mendapat suatu perhatian. Adanya perubahan-perubahan yang terjadi tersebut memiliki respon serta persepsi yang berbeda dari setiap individu khususnya adalah para lanjut usia

\section{PEMBAHASAN}

\section{Dampak Psikologis}

Dampak secara psikologis yang timbul dalam kesiapan memasuki masa pensiun bagi lanjut usia meliputi aspek kesehatan, aspek ekonomi dan aspek sosial (Kartinah \& Sudaryanto, 2017). Lanjut usia dapat dikatakan mandiri apabila memiliki kondisi kesehatan yang baik. Kondisi kesehatan ini bisa diketahui saat lanjut usia mengikuti kegiatan di Bina Keluarga Lansia (BKL) posyandu Cempaka, dengan beragam keluhan-keluhan umum lansia yang dirasakannya. Penurunan kondisi fisik lanjut usia ini akan berpengaruh pada kondisi psikisnya. Dari aspek ekonomi, memiliki penghasilan serta dapat memenuhi kebutuhan hidupnya sehari-hari. Perubahan yang terjadi akan sangat memberikan pengaruh yang besar seperti berkurangnya pendapatan yang diterima, berkurangnya fasilitas yang diperoleh selama ini, dan lain sebagainya. Lanjut usia dengan kondisi fisik serta psikis yang menurun menyebabkan pula hasil pekerjaan yang kurang maksimal. Secara sosial, lanjut usia dapat melakukan aktivitas sosial serta memiliki hubungan yang baik melalui dukungan yang diberikan oleh keluarga maupun masyarakat. Memasuki masa pensiun akan memberikan pengaruh dalam kehidupan lanjut usia baik secara finansial, fisik, mental dan emosional.

\section{Kemandirian Hidup}

Hasil penelitian menunjukkan bahwa kemandirian lanjut usia dalam membangun hidup dan gambaran kehidupan lanjut usia di Bina Keluarga Lansia (BKL) Posyandu Cempaka Kabupaten Ngawi bersifat relatif. Aktivitas kehidupan sehari-hari dalam kemandirian hidup ini memberikan pengaruh besar. Kemandirian hidup lanjut usia dalam aktivitas kehidupan sehari-hari didefinisikan sebagai kemampuan atau kemandirian seseorang dalam melakukan aktivitas dan fungsi-fungsi kehidupan sehari-hari yang dilakukan oleh lanjut usia secara rutin, menyeluruh dan berkesinambungan. Hal ini dapat terlihat dari aktivitas kehidupan sehari-hari lansia di tengah-tengah masyarakat yakni dapat menyesuaikan diri dengan perubahan yang terjadi. Kemampuan seseorang untuk melakukan activity daily living secara mandiri dapat dikatakan sukses atau berhasil apabila lanjut usia mampu melakukan penerimaan terhadap usia tua dengan baik (Triningtyas \& Muhayati, 
2018). Kondisi-kondisi yang mempengaruhi dalam hal ini meliputi kondisi ekonomi, lanjut usia dapat mandiri apabila secara ekonomi memiliki penghasilan dan dapat memenuhi kebutuhan hidup sehari-harinya. Untuk memenuhi kebutuhan tersebut, hampir sebagian besar lanjut usia masih tetap melakukan aktivitas dengan bekerja. Mengingat sudah memasuki masa lanjut usia, maka aktivitas yang dilakukan menyesuaikan dengan kondisi fisik atau kesehatannya. Kondisi kesehatan sangat berpengaruh sekali, baik secara fisik maupun psikis. Sementara untuk aktivitas sosial, ada beragam kegiatan-kegiatan yang bersifat sosial yang dapat dipilih oleh para lansia sesuai dengan kebutuhan yang diperlukan. Melalui berbagai aktivitas sosial yang diikuti, sesama para lanjut usia dapat berkumpul bersama teman yang sebaya dengan usianya. Hal tersebut dengan tegas juga diungkapkan oleh (Uraningsari \& Djalali, 2016), yang menyatakan bahwa jika komunitas lansia bergaul dengan orang-orang sebaya, maka lingkungan mendukung keberadaan lansia yang samasama sudah lanjut usia.

\section{Penerimaan Diri}

Hasil penelitian menunjukkan bahwa penerimaan diri lanjut usia di Bina Keluarga Lansia (BKL) Posyandu Cempaka Kabupaten Ngawi memiliki pengaruh yang besar. Masa tua merupakan proses alami yang akan terjadi pada setiap makhluk hidup. Semua makhluk hidup memiliki siklus kehidupan menuju tua yang diawali dengan proses kelahiran, tumbuh menjadi dewasa, berkembang biak, menjadi tua dan akhirnya tutup usia (Suardiman, 2011). Usia tua rentan terhadap penyakit. Beberapa kelemahan dan penyakit akan terjadi dengan bertambahya usia. Lanjut usia yang hidup dalam kelemahan, dan berbagai penyakit yang dirasakannya tentu tidak akan dapat menikmati masa tuanya dengan baik. Akan berbeda apabila lanjut usia yang dapat menerima dirinya. Individu yang tidak bermasalah dengan dirinya sendiri, tidak memiliki beban perasaan terhadap diri sendiri, sehingga individu lebih banyak memiliki kesempatan untuk beradaptasi dengan lingkungannya (Uraningsari \& Djalali, 2016). Perubahan yang dirasakan seperti proses menua dapat diterima oleh lanjut usia dengan baik serta mampu menyesuaikan dirinya dengan lingkungannya dimana ia berada. Keadaan fisik seseorang akan mempengaruhi tingkat penerimaan diri. Secara umum, dapat disimpulkan bahwa penerimaan diri pada lanjut usia yakni individu mampu menerima kelebihan dan kekurangan dirinya serta mau hidup berdamai dengan keadaan tersebut. Lanjut usia yang mampu menerima dirinya atau tidak juga mendapat pengaruh dari lingkungan dimana ia berada. Hal senada juga diungkapkan dalam sebuah penelitian yang dilakukan oleh (Hariyadi, 2014), yang menyatakan bahwa seseorang yang dapat menerima dirinya mempunyai penilaian yang realistik terhadap potensi yang ada pada dirinya dan penilaian yang positif akan harga dirinya, karakteristik yang dimiliki dengan penerimaan diri akan diterimanya sebagai suatu anugerah. Segala hal yang menyenangkan yang terjadi pada diri individu akan dapat membuatnya menikmati kehidupan.

\section{Motivasi Lansia}

Motivasi yang melatar-belakangi kondisi lanjut usia dalam membangun kemandirian hidup dan penerimaan diri terhadap kesiapan memasuki masa pensiun di Bina Keluarga Lansia (BKL) Posyandu Cempaka Kabupaten Ngawi perlu menjadi teladan bagi para lanjut usia yang lain. Bagi mereka para lanjut usia yang sangat aktif dalam mengikuti kegiatan di posyandu lansia memperoleh beragam manfaat bagi lansia itu sendiri.

Berdasarkan jumlah data lanjut usia yang diperoleh diatas bahwa mereka (para lanjut usia) sangat aktif dalam mengikuti kegiatan di Bina Keluarga Lansia Posyandu Cempaka Dusun Pojok Desa Beran Kecamatan Ngawi Kabupaten Ngawi. Adapun bentuk-bentuk kegiatan yang dilakukan meliputi tersedianya fasilitas kesehatan di posyandu lansia khususnya posyandu Cempaka yang secara rutin menggelar berbagai aktivitas untuk para lanjut usia. Dukungan yang besar dari kaderkader posyandu Cempaka ini yang memotivasi para lanjut usia agar mengikuti kegiatan posyandu lansia.

Kegiatan posyandu lansia yang berjalan dengan baik akan memberi kemudahan bagi lansia dalam mendapatkan pelayanan kesehatan dasar, sehingga kualitas hidupnya di masyarakat tetap terjaga dengan baik dan optimal. Memasuki lanjut usia merupakan proses alami yang tidak dapat dihindari. Lanjut usia, khususnya di Dusun Pojok dapat membangun kemandirian hidup dengan baik. Di usia yang sudah lanjut ini, mereka (para lanjut usia) masih melakukan aktivitasnya dengan melakukan pekerjaan di sawah.

\section{Konseling Lansia}

Berbicara lanjut usia, penuaan merupakan bagian alami dari proses perkembangan. Terjadinya perubahan yang berhubungan dengan penuaan menimbulkan masalah uatama bagi lanjut usia, 
seperti kesepian, sakit, memasuki masa pensiun, rasa malas, dan kehilangan. Menurut Havighurst (Gladding, 2012), lansia dituntut agar bisa belajar mengatasi hal yang terjadi berikut, seperti meninggalnya teman dan pasangan, menurunnya kekuatan fisik, pensiun dan berkurangnya pendapatan, waktu bersantai yang lebih banyak dan proses memiliki teman baru, berkembangnya peran sosial baru, mengubah perencanaan hidup. Secara menyeluruh, penuaan adalah masa bagi transisi dan transformasi.

Upaya Lanjut Usia Dalam Membangun Kemandirian Hidup dan Penerimaan Diri Terhadap Kesiapan Memasuki Masa Pensiun (Studi Pada Lansia di Bina Keluarga Lansia Posyandu Cempaka Kabupaten Ngawi melalui Konseling Lansia. Memberi konseling pada lansia memerlukan latihan yang profesional. Bagi seorang konselor yang tidak dapat memahami lansia merupakan suatu hal yang mustahil akan dapat membantu lansia tersebut. Keterlibatan langsung dengan menggunakan strategi pengendalian yang baru dilakukan sebagai upaya meminimalisir terhadap masalah-masalah yang dihadapi oleh para lanjut usia.

Layanan konseling bagi lansia akan tepat diberikan dan sangat membantu apabila fleksibel dan praktis serta berfokus langsung pada penyelesaian masalah yang dihadapi oleh lanjut usia. Dalam konseling lanjut usia terdapat ragam pelayanan, yang meliputi preventif/pencegahan, kuratif/penyembuhan dan rehabilitatif/pemulihan kembali. Preventif atau pencegahan, merupakan pelayanan bimbingan dan konseling yang diarahkan untuk pencegahan timbulnya masalah baru dan meluasnya permasalahan khususnya di usia lanjut. Kuratif atau penyembuhan, merupakan pelayanan sosial usia lanjut yang diarahkan untuk penyembuhan atas gangguan-gangguan yang dialami usia lanjut, baik secara fisik, psikis, maupun sosial. Rehabilitatif atau pemulihan kembali merupakan proses pemuihan kembali fungsi-fugsi sosial setelah individu mengalami berbagai gangguan dalam melaksanakan fungsi-fungsi sosialnya.

\section{SIMPULAN DAN SARAN}

Berdasarkan hasil dan pembahasan diatas, dapat dismpulkan bahwa kemandirian hidup lansia bersifat relatif. Dampak psikologis yang timbul dalam kesiapan memasuki masa pensiun bagi lanjut usia dipengaruhi oleh berbagai faktor seperti dukungan keluarga, kesehatan dan juga ekonomi. Adanya pemahaman dan membangun kemandirian hidup dan penerimaan diri terhadap kesiapan memasuki masa pensiun di Bina Keluarga Lansia (BKL) Posyandu Cempaka Kabupaten Ngawi melalui Konseling Lansia kepada para lanjut usia. Layanan konseling bagi lansia akan tepat diberikan dan sangat membantu apabila fleksibel dan praktis serta berfokus langsung pada penyelesaian masalah yang dihadapi oleh lanjut usia.

\section{DAFTAR RUJUKAN}

Barlian, N. A. (2016). Pengaruh Tipe Kepribadian, Kontrak Psikologis, Komitmen Organisasi, motivasi Dan Kepuasan Kerja Terhadap Organizational Citizenship Behavior (OCB) Dan Kinerja Karyawan Di Rumah Sakit ParuKabupaten Jember. Jurnal Relasi Stie Mandala Jember, 12(1), 366-373.

BKKBN. (2015). Buku Saku Kegiatan KKN Mahasiswa. Surabaya: Perwakilan BKKBN Provinsi Jawa Timur.

Etikan, I., Musa, S. A., \& Alkassim, R. S. (2016). Comparison of convenience sampling and purposive sampling. American Journal of Theoretical and Applied Statistics, 5(1), 1-4.

Fardila, N., Rahmi, T., \& Putra, Y. Y. (2017). Hubungan Dukungan Sosial Keluarga dengan Kesiapan Menghadapi Pensiun Pada Pegawai Negeri Sipil. Jurnal RAP, 5(2), 157-168.

Gladding, S. T. (2012). Konseling Profesi yang Menyeluruh. Jakarta: Indeks.

Hammersley, M. (2018). Routledge Revivals: The Dilemma of Qualitative Method (1989): Herbert Blumer and the Chicago Tradition. New York: Routledge.

Hariyadi, Y. (2014). Hubungan Antara Penerimaan Diri Lansia dengan Angka Harapan Hidup di Kelurahan Wates Kota Mojokerto. Medica Majapahit, 6(2), 78-95.

Hurlock, E. B. (2008). Psikologi Perkembangan: Suatu Pendekatan Sepanjang Rentang Kehidupan. Jakarta: Erlangga.

Kartinah, K., \& Sudaryanto, A. (2017). Masalah Psikososial Pada Lanjut Usia. Berita Ilmu Keperawatan, 1(2), 93-96.

Marlita, L., Saputra, R., \& Yamin, M. (2018). Faktor-Faktor yang Mempengaruhi Tingkat Kemandirian Lansia dalam Melakukan Activity Daily Living (ADL) di UPT PSTW Khusnul Khotimah. Jurnal 


\section{Jurnal Konseling Indonesia}

http://ejournal.unikama.ac.id/index.php/JKI

Keperawatan Abdurrab, 1(2), 64-68.

Mönks, F. J., Knoers, A. M. P., \& Haditono, S. R. (1985). Psikologi Perkembangan: Pengantar dalam berbagai bagiannya. Yogyakarta: Gadjah Mada University Press.

Safitri, B. R. (2013). Kesiapan Menghadapi Masa Pensiun Ditinjau dari Peran Gender Karyawan. Jurnal Ilmiah Psikologi Terapan, 1(2), 191-204.

Suardiman, S. P. (2011). Psikologi: Usia Lanjut. Yogyakarta: Gadjah Mada University Press.

Supratiknya, A. (1995). Komunikasi Antar Pribadi, Tinjauan Psikologis. Yogyakarta: Kanisius.

Triningtyas, D. A., \& Muhayati, S. (2018). Activity Daily Living : Studi Pada Lanjut Usia di Bina Keluarga Lansia Posyandu Cempaka Kabupaten Ngawi. In Prosiding Seminar Nasional Universitas Muhammadiyah Semarang.

Uraningsari, F., \& Djalali, M. A. (2016). Penerimaan Diri, Dukungan Sosial dan Kebahagiaan Pada Lanjut Usia. Persona: Jurnal Psikologi Indonesia, 5(1), 15-27.

Yusuf, A., Nihayati, H. E., \& Abidin, Z. (2017). Cognitive Therapy Decrease the Level of Depression. Jurnal Ners, 3(2), 163-169. 